[0212-7199 (2007) 24: 1; pp 31-34] ANALES DE MEDICINA INTERNA Copyright $\odot 2007$ ARAN EDICIONES, S.L.

AN. MED. InTERnA (Madrid) Vol. 24, N. ${ }^{\circ} 1$, pp. 31-34, 2007

\title{
Síndrome de Ramsay-Hunt
}

\author{
A. MARTÍNEZ OVIEDO, M. T. LAHOZ ZAMARRO'1, J. J. UROZ DEL HOYO ${ }^{2}$

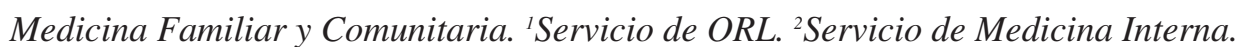 \\ Hospital General Obispo Polanco. Teruel
}

RAMSAY-HUNT SYNDROME

\section{RESUMEN}

El síndrome de Ramsay Hunt asocia parálisis facial periférica acompañada de una erupción vesicular en pabellón auricular o cavidad oral, causada por la afectación del ganglio geniculado por el virus varicelazoster (VVZ). Supone la segunda causa más frecuente de parálisis facial periférica atraumática. Presentamos una revisión de 10 casos con síndrome de Ramsay Hunt que requirieron ingreso en nuestro hospital durante el periodo 2001-2005. Destacamos varios casos atípicos con afectación de otros pares craneales, un caso complicado con cerebelitis y mielopatía, así como la presencia de neumonía en 3/10, que sugiere un estado inmunocomprometido en estos pacientes. La respuesta al tratamiento con aciclovir y prednisona fue satisfactoria en la mayoría de los casos. La afectación facial en el zóster ótico es inicialmente más severa y con peor pronóstico de recuperación que la parálisis de Bell.

PALABRAS CLAVE: Síndrome de Ramsay Hunt. Zóster ótico. Parálisis facial. Virus varicela-zóster.

\begin{abstract}
Ramsay Hunt syndrome is a peripheral facial nerve palsy accompanied by an erythematous vesicular rash on the ear or in the mouth; it is caused by varicella zoster virus that affects the geniculate ganglion. The zoster oticus is the second most common cause of atraumatic peripheral facial paralysis. We present a review of zoster oticus identified in our hospital among 2001-2005. we show various atypical cases with multiple cranial nerve involvement; cerebellum and spinal cord was affected in one patient. 3/10 cases were complicated with a pneumonia. So, we think that some grade of immunodeficiency may be present in these cases. Treatment with acyclovir and prednisone has been successfully to improve the outcome in the most of patients. Compared with Bell's palsy, patients with zoster oticus often have more severe paralysis at onset and are less likely to recover completely.
\end{abstract}

KEY WORDS: Ramsay-Hunt syndrome. Zoster oticus. Facial paralysis. Varicella zoster virus.

Martínez Oviedo A, Lahoz, Zamarro MT, Uroz del Hoyo JJ. Síndrome de Ramsay-Hunt. An Med Interna (Madrid) 2007; $24: 31$-34.

\section{INTRODUCCIÓN}

El herpes zóster ótico, descrito por Ramsay Hunt en 1907, es un síndrome que asocia parálisis facial periférica y vesículas en pabellón auricular ipsilateral o boca, como consecuencia de la afectación del ganglio geniculado por el virus de la varicelazoster (1). A menudo están presentes otros signos y síntomas como hipoacusia, nauseas, vómitos, vértigo y nistagmus debido a la afectación del VIII par craneal por proximidad (2).

En estudios recientes, se estima que este síndrome supone entre el $7-16 \%$ del total de las parálisis faciales periféricas unilaterales no traumáticas, con una incidencia similar en adultos y en niños mayores de seis años $(3,4)$. La afectación facial suele aparecer entre 4 y 15 días después de la erupción, su evolución es más severa que la parálisis facial de Bell, y la recuperación completa sólo sucede en el 50\% de los adultos y el $78 \%$ de los niños $(1,3)$.

Los sujetos inmunodeprimidos están particularmente expuestos a desarrollar esta enfermedad, especialmente los que reciben un tratamiento inmunosupresor, individuos infectados por el virus VIH y los portadores de enfermedades malignas hematológicas.

La presentación clínica es muy variada, lo que ha llevado a clasificarla clásicamente en 4 estadios (5). Estadio I: asocia otalgia y erupción de vesículas en el territorio del nervio facial. Estadio II: incluye además de lo anterior, una parálisis facial periférica homolateral. Estadio III o síndrome de Sicard, a la triada de dolor-erupción-parálisis facial se añaden acúfenos e hipoacusia perceptiva de difícil recuperación y más adelante una crisis vertiginosa. El estadio IV se carac-

Trabajo aceptado: 24 de julio de 2006 
teriza por la afectación de otros pares craneales, en particular el V.

Presentamos una revisión de los casos con síndrome de Ramsay-Hunt que requirieron ingreso en nuestro hospital durante el periodo 2001-2005.

\section{CASOS APORTADOS}

En el periodo mencionado se hallaron 10 casos con síndrome de Ramsay Hunt que ingresaron para tratamiento endovenoso o presentaron un zóster ótico estando ingresados por otro motivo. La edad media de los pacientes fue de 63 años, con una distribución similar en ambos sexos.

Los síntomas más comunes de presentación fueron los siguientes: otalgia, dolor en hemicara y pabellón auricular, malestar general, acompañados más tarde de acúfeno, hipoacusia (40\%), vértigo (70\%) y erupción vesiculo-costrosa en todos los casos. La parálisis facial apareció en el 90\% de los casos, generalmente entre 3 y 7 días tras los síntomas descritos previamente.

En 3 casos las manifestaciones clínicas fueron más atípicas: en uno de ellos, un varón de 60 años sin antecedentes personales de interés, la erupción herpética afectó la rama mandibular del trigémino así como el dermatoma de $\mathrm{C} 1$ ipsilateral (Fig. 1) cuatro días después presentó una parálisis facial izquierda, vértigo intenso e hipoacusia neurosensorial del mismo lado.

En otro, un varón de 80 años en tratamiento con imnunodepresores y corticoides por una artritis reumatoide y EPOC severo, la erup- ción en el área de Ramsay Hunt fue mínima y pasó desapercibida, presentando el paciente una parálisis facial que se diagnosticó de zóster ótico al observar en la cavidad oral, unas ulceraciones en paladar y 2/3 anteriores de lengua ipsilaterales que respetaban la línea media, además de hipoacusia neurosensorial y vértigo periférico (Fig. 2).

En el tercero de los pacientes, en tratamiento antirretroviral para el VIH, la erupción herpética fue más amplia, afectando varios pares craneales, entre ellos las tres ramas del trigémino, VIII y VII par sin afectación motora.

En 9/10 pacientes se instauró tratamiento con aciclovir, añadiendo prednisona en los casos de parálisis facial. La mejoría de la función facial fue progresiva, quedando secuelas tan solo en el $20 \%$. La hipoacusia neurosensorial persistía en controles posteriores.

Entre las complicaciones destacamos las neuralgias postherpéticas (20\%), que mejoraron al cabo de algunos meses, un caso con ataxia cerebelosa y mielopatía inflamatoria con tal pérdida de fuerza en extremidades que llegó a imposibilitar la deambulación a pesar del tratamiento con aciclovir, quedando una marcha atáxica residual como secuela. En este caso la administración de esteroides se realizó de forma tardía.

La sobreinfección respiratoria fue una complicación frecuente en nuestra serie 4/10, diagnosticándose una neumonía en 3 pacientes, uno de ellos con afectación pulmonar previa severa que provocó su fallecimiento. Un cuadro vertiginoso periférico por hipofunción vestibular ipsilateral permanente fue descrito en un caso, el cual no recibió tratamiento al consultar de forma tardía desde el inicio de los síntomas.

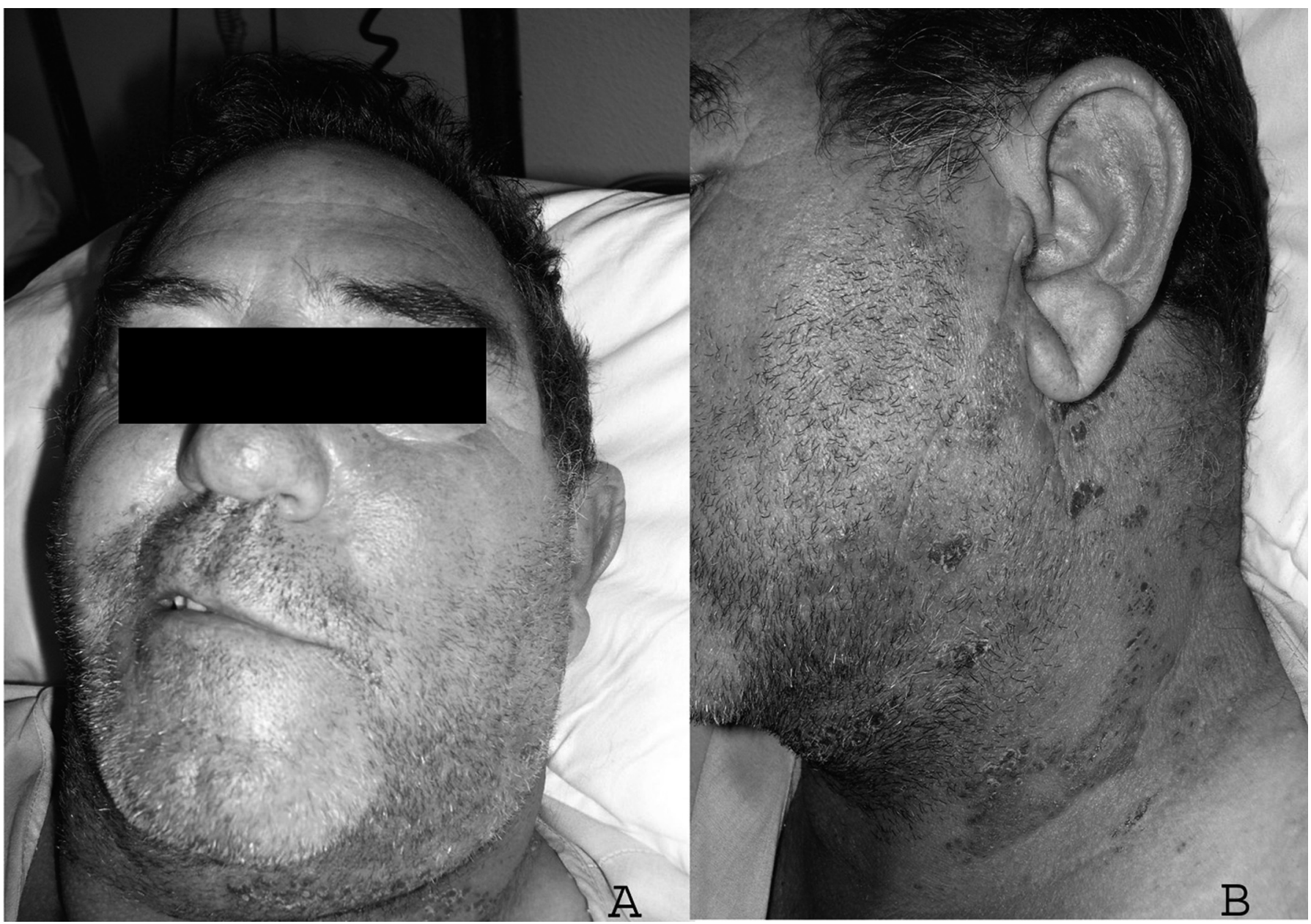

Fig. 1. (A) Paciente con parálisis facial izquierda. (B) Erupcion vesículo-costrosa en rama mandibular del trigémino y dermatoma C1. 


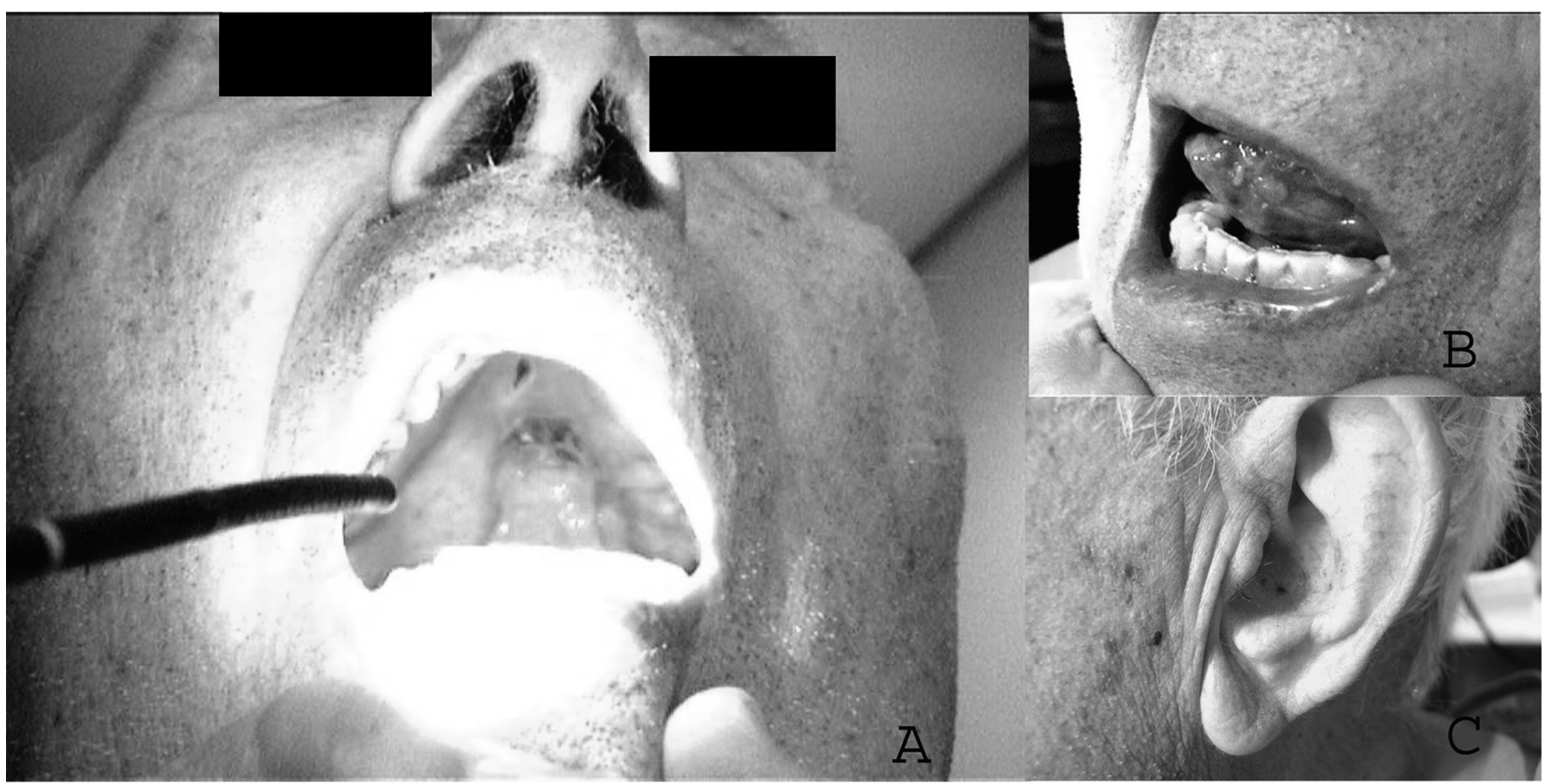

Fig. 2. (A) Ulceración en paladar blando que respeta línea (territorio $V_{2}$ ). (B) Ulceración en borde lateral de la lengua zona ipsilateral. (C) Mínima afectación en el área de Ramsay-Hunt en pabellón auricular.

\section{DISCUSIÓN}

La parálisis facial es generalmente la secuela más frecuente e importante, suele alcanzar su máxima intensidad dentro de la primera semana desde el comienzo de los síntomas. En correlación con otros estudios, la parálisis completa y la edad mayor de 50 años se han definido como factores pronósticos desfavorables para su recuperación (2).

La presentación del síndrome de Ramsay Hunt como una polineuropatía de varios pares craneales ya fue descrito por Aviel y Marshak (5), que revisando la literatura encontraron la participación de los siguientes nervios en orden decreciente: VII, VIII, IX, V, X y VI, siendo rara la participación del resto de pares craneales. Otros fenómenos descritos son la afectación de dermatomas cervicales, encefalitis, síndrome de Horner, uveítis por zoster y SIADH (5-7).

Las manifestaciones clínicas dependerán en gran medida del territorio o territorios que inervan los pares craneales afectados, siendo su característica esencial ser estrictamente unilateral, deteniéndose en línea media. La sobreinfección de las lesiones, sobre todo las orofaríngeas, es frecuente y puede enmascarar el cuadro clínico, como en uno de nuestros pacientes.

El diagnóstico en la mayoría de los casos es clínico, por su evolución y carácter metamérico, pero a veces éste es difícil, debido a la variabilidad en su presentación clínica como hemos expuesto anteriormente. El aislamiento e identificación del virus o en su defecto la serología seriada puede ser útil en casos atípicos. Las técnicas de biología molecular mediante análisis por PCR de exudados óticos han mostrado su positividad en el $75 \%$ de los casos antes de que aparezcan las vesículas (8). Generalmente estas técnicas nos confirman el diagnóstico de forma tardía, ya que no están disponibles en la mayoría de los centros.

En ocasiones la resonancia magnética nuclear se ha utilizado para el diagnóstico, aunque sus hallazgos son inespecíficos y únicamente estaría indicada cuando se vaya a realizar una descompresión quirúrgica del nervio (9). Esta técnica se reserva para casos con neuralgias resistentes, con resultados dispares (10).

Aunque la aparición de las vesículas suele ser anterior a la parálisis facial, en un 14\% de los casos esta erupción es posterior8. En otros casos las vesículas herpéticas no llegan a aparecer, aunque es posible aislar DNA de virus VVZ en piel, saliva, células mononucleares o exudados del oído medio; a esta entidad se conoce como zoster sine herpete y en algunos estudios supone el $16 \%$ del total de las parálisis faciales periféricas $(4,11)$. Así una pequeña proporción de pacientes diagnosticados inicialmente de parálisis idiopática de Bell, son en realidad zoster sine herpete o síndrome de Ramsay Hunt atípicos.

El tratamiento con aciclovir durante 7 días ha demostrado mejorar el pronóstico de la parálisis facial asociada al zóster ótico si se inicia en los 3 primeros días desde el comienzo de la clínica, con recuperación completa en el $75 \%$ de los pacientes (12). El uso de esteroides es más controvertido, aunque en general se recomienda durante 10 días por su efecto antiinflamatorio en caso de parálisis facial (13). El tratamiento endovenoso se recomienda en los pacientes inmunodeprimidos y en los estadios II, III y IV.

En relación a las complicaciones, la neuralgia postherpética suele ser la más frecuente, seguida de neuropatías, meningoencefalitis e incluso mielitis como en uno de nuestros casos (6). Generalmente éstas suelen ser más graves cuanto mayor es la imunodepresión del paciente, que en muchas ocasiones se agrava al administrar esteroides.

El seguimiento estrecho es necesario para detectar las complicaciones, pues en muchas ocasiones, como hemos visto anteriormente, se trata de pacientes inmunocomprometidos. Es importante pensar en ella ante todo parálisis facial dolorosa, se acompañe o no de erupción cutánea y afectación vestibular, puesto que el diagnóstico y tratamiento precoces aminora las secuelas de esta enfermedad. 


\section{Bibliografía}

1. Sweeney CJ, Tilden DH. Ramsay Hunt syndrome. J Neurol Neurosurg Psychiatry 2001; 71: 149-54.

2. Kuhweide R, Van de Steene V, Vlaminck S, Casselman JW. RamsayHunt syndrome: pathopysiology of cochleovestibular symptoms. J Laryngol Otol 2002; 116: 844-8.

3. Hato N, Kisaki H, Honda N, Gyo K, Murakami S, Yanagihara N. Ramsay Hunt syndrome in children. Ann Neurol 2000; 48: 254-6.

4. Peitersen E. Bell's palsy: the spontaneous course of 2500 peripheral falcial nerve palsies of different etiologies. Acta Otolaryngol (Suppl.) 2002; 594: 4-30

5. Aviel A, Marsahak G. Ramsay Hunt syndrome: a cranial polyneuropathy. Am J Otolaryngol 1982; 3: 61-6

6. Sanchez-Guerra M, Infante J, Pascual J, Berciano J, Polo J. Neurologic complications of herpes zoster. A retrospective study in 100 patients. Neurología 2001; 16: 112-7

7. Kagayama Y, Nakamura M, Sato A, Sato M, Nakayama S, Komatsuzaki O, Furuda H. Syndrome of inappropiate secretion of antidiuretic hormona (SIADH) associated with Ramsay Hunt syndrome: report of a case and review of the literature. Japanese $\mathbf{J}$ Med
1989; 28: 219-22.

8. Murukami S, Honda N, Mizobuchi M, Nakashiro Y. Hato N, Gyo K. Rapid diagnosis of varicella zoster virus infection in acute facial palsy. Neurology 1998; 51: 1202-5

9. Jonsson L, Tien R, Engström M, Thuomas KA. Gd-DPTA enhanced MRI in Bell's palsy and herpes zoster oticus: an overview and implications for future studies. Acta Otolaryngol 1995; 115: 577-84.

10. Morow MJ. Bell's palsy and herpes zoster oticus. Curr Treat Options Neurol 2000; 2: 407-16

11. Terada K, Niizuma T, Kawano S, Kataoka N, Adisada T, Orita Y. Detection of varicella-zoster virus DNA in peripheral mononuclear cell from patients with Ramsay Hunt síndrome or zoster sine herpete. J Med Virol 1998; 56: 359-63

12. Uri N, Greenberg E, Kitzes-Cohen R, Doweck I. Acyclovir in the treatment of Ramsay Hunt syndrome. Otolaryngol Head Neck Surg 2003; 129: 379-81.

13. Kinishi M, Amatsu M, Mohori M, Saito M, Hasegawa T, Hasegawa S. Acyclovir improves recovery rate of facial nerve palsy in Ramsay Hunt syndrome. Auris Nasus Larynx 2001; 28: 223-6. 